\title{
A forma e a forja da beleza: medidas desinteressadas entre Marx e Kant
}

Rodney Ferreira

\section{Resumo}

As noções de liberdade e desinteresse se entrelaçam na recepção estética kantiana do belo e na produção do homem concebida pelo jovem Marx - esta é a premissa deste trabalho, que tem em vista considerar as proximidades estéticas postuladas na Crítica da faculdade de julgar e nos Manuscritos econômico-filosóficos, a partir das seguintes impressões: as condições similares de necessidade do universal subjetivo e da produção e recepção em conformidade com fins formais que desconsideram necessidades físicas e morais. As dificuldades iniciais são: se, em Marx, a produção é desinteressada, mas a recepção visa algum fim, e o que se define por finalidade em cada um dos autores; e se há a noção de objeto belo em Marx, determinada pela produção segundo leis efetivamente constituídas por uma condição natural do belo ou se pela recepção do sujeito enquanto identificando sua própria expressão no objeto, e como isso se relaciona com o juízo de gosto kantiano. Assim, talvez seja mais preciso dizer que se aposta em uma proposta antes de delineamentos do que de proximidades. Palavras-chave: Estética - Liberdade - Conformidade a fins. 


\section{Introdução}

Em Kant, a liberdade é fundamentalmente um exercício moral legislativamente determinado no domínio da filosofia prática, porém sua dimensão não é abarcada integralmente pelos fins da faculdade que a legisla. Para alcançar a unificação sistêmica com a filosofia teórica, foi preciso conceber uma região da espontaneidade indeterminada onde o conhecimento da natureza encontrasse a visão de sua própria autonomia - o que se realiza no juízo de gosto. Isto porque o juízo estético é também um livre exercício das faculdades da imaginação e do entendimento em conformidade a fins, uma vez que se define pelo desinteresse e por ser uma forma de subjetivo universal; uma atividade do juízo que possui apenas a aparência de objetivo-lógico. Assim seguindo, a concepção de liberdade do jovem Marx, caracterizada como uma produção do homem na natureza que não é movida por uma necessidade física imediata, aproxima-se dessa do juízo estético, ao serem definidas essencialmente pela relação de desinteresse e livre exercício das capacidades do sujeito em relação às formas da natureza. Nota-se, ergo, que o material de suas réguas é o mesmo. Mas quais são as respectivas medidas de desinteresse que utilizam Kant e o jovem Marx?

\section{I.I. Juízo de gosto}

Se considerado como o fundamento da satisfação, todo fim carrega consigo um interesse como fundamento de determinação do juízo sobre o objeto do prazer. Assim, o juízo de gosto não pode ter um fim subjetivo por fundamento. Mas também não pode ser determinado por uma representação de um fim objetivo, isto é, relativo à possibilidade do próprio objeto segundo princípios de ligação finalística, ou seja, por um conceito do bem (KANT, 20I6, p. II7).

Dando ênfase ao aspecto extrassistêmico do desenvolvimento do juízo estético em Kant, isto é, aderindo àqueles mesmos princípios conciliadores e inauguradores do projeto da crítica que se referiam à antitética histórico-filosófica, e não simplesmente ao estabelecimento de uma nova dogmática com base em um sistema transcendental ${ }^{\mathrm{I}}$, pode-se dizer que a centralidade da discussão es-

I A crítica kantiana será conciliadora não apenas na medida em que o método crítico se põe como um tribunal para as deduções perpetradas por céticos e dogmáticos, e assim se coloca como um tribunal 
tética se dá na necessidade de estabelecer princípios universais para algo que é próprio de um aprazimento subjetivo, desembaraçando os imbróglios daqueles que até então trataram essas categorias como opostas e acabaram por se entregar a uma determinação submetida ao conceito, ou fazendo com que a perfeição, que é algo próprio do juízo determinante como multiplicidade de composição do conceito, passasse por beleza, ou, então, que o agradável subjetivo, que é próprio dos sentidos, o fizesse.

Para tanto, coube considerar que o belo puro deve ser um aprazimento desinteressado, um aprazimento que não é determinado por nenhum juízo dos sentidos, e que portanto não diz respeito às necessidades ou aos desejos imediatos do sujeito - que encontraria no objeto de agrado uma forma de incitá-los e saciá-los. Tampouco se trata de um juízo lógico objetivo, em que a complacência se determinaria no bom, que é definido segundo conceitos e que também diz respeito a um interesse por uma finalidade - e aqui o problema se dá tanto com respeito à finalidade moral quanto à destituição do subjetivo, uma vez que se passa ao conceito determinado, que é um objetivo universal. Se é assim, o juízo estético do belo deve estar em um meio termo entre as faculdades da imaginação e do entendimento, de modo que a representação que se dá na primeira se coadune com o entendimento em vistas de uma referência ao conceito que só pode ter um fim aparente, gerando um excitamento das faculdades que as põe em conformidade a um fim conceitual, mas que não chega de fato, em se tratando do belo puro e simples, à determinação do conceito. Trata-se de um estado de ânimo (Gemüt), acionado pela mera representação no sujeito, disposto ao fim, mas sem a necessidade de chegar a ele, e portanto sem se objetivar. Esse livre jogo harmônico das faculdades que o belo puro gera é um princípio de adesão universal, mas que se mantém no sujeito enquanto mera recepção da faculdade sensível e mera atividade desinteressada do juízo, que então ganha a condição reflexiva: percepção do externo não como condicionante, mas como mero estímulo, garantindo a autonomia e espontaneidade de sua própria aspiração interna enquanto faculdade.

que contempla o fundamento mesmo das pretensões e avalia sua coerência ou invalidade, mas é também conciliadora na medida em que, para determinar a origem do objeto de conhecimento, fez-se preciso que o entendimento não fosse mero produto de suas relações imediatas no empírico, mas tivesse em si princípios organizadores a priori, isto, metafísicos e transcendentais. Essa conciliação se torna inauguração quando a consequência dessa organização do entendimento resulta que a origem do objeto do conhecimento e o próprio conhecimento, portanto, não se deem em si, mas como fenômenos. 


\section{I.II. Produção e belo}

É verdade que também o animal produz. Constrói para si um ninho, habitações, como a abelha, castor, formiga etc. No entanto, produz apenas aquilo de que necessita imediatamente para si ou sua cria; produz unilateral[mente], enquanto o homem produz universal[mente]; o animal produz apenas sob o domínio da carência física imediata, enquanto o homem produz mesmo livre da carência física, e só produz, primeira e verdadeiramente, na [sua] liberdade [com relação] a ela; [...]. O animal forma apenas segundo a medida e a carência da species à qual pertence, enquanto o homem sabe produzir segundo a medida de qualquer species, e sabe considerar, por toda a parte, a medida inerente ao objeto; o homem também forma, por isso, segundo as leis da beleza (MARX, 2004, p. 85).

Não se pode falar do belo, no jovem Marx, sem tratar das condições intrínsecas ao trabalho e à relação com a natureza sensível, bem como de sua atividade negadora: a alienação. O trabalhador nada pode criar sem as condições externas providas pela natureza, de maneira que o externo sensível se faz condição para toda e qualquer criação do homem (MARX, 2004, p. 8I) enquanto ser envolvido por dois tipos de meios de vida: aqueles determinados por sua relação com os objetos de trabalho produzidos através da matéria natural, no qual o homem exerce o trabalho como expressão, e aqueles que determinam sua subsistência física, ou seja, suas necessidades animais imediatas. Todavia, para Marx, o regime de produção não se dá realmente assim, pois o que se demanda é um paulatino aumento da apropriação da matéria sensível em prol de objetos de trabalho, e não de expressão. Isto é, o trabalhador passa a ser ele mesmo parte da demanda da produção, e sua categoria de eficiência depende de quanto produz, do montante de objetos que resulta de seu desgaste em múltiplos sentidos - a essência do modo de produção capitalista analisado por Marx é definida pela centralidade da relação alienada do trabalhador com seu objeto de trabalho, em que o trabalhador não se vê expresso no objeto, mas ele próprio objetificado ao ser reduzido à condição de mero sujeito físico reprodutor. O seu objeto não é seu, mas algo alheio, pois se trata do produto de sua objetificação. Junta-se a isso o fato de que o próprio modo de produção é externo ao trabalhador, na medida em que faz deste uma força condicionada e infeliz servindo à eficácia acumulativa e maquínica ${ }^{2}$. A partir disso, Marx

2 Cf. Tempos Modernos (I936), para brilhante retratação da miséria física e psíquica do operariado perpetrada pelas formas fabris. 
afirma que o trabalhador só pode se sentir junto a si quando fora do trabalho, mas se vê fora de si quando no trabalho (MARX, 2004, p. 83). É interessante observar a ambiguidade presente no fato de que o homem parece se animalizar como forma de preservar, dessa objetificação, ainda algo de seu meio - e assim faz de seu conforto, enquanto trabalhador em condição miserável, aquilo que é parte de sua condição de animal: comer, procriar, dormir... O que, no entanto, indica apenas que o trabalhador se prende em um processo retroativo de redução ao imediato físico: seu comer é utilitário, seu procriar é castrativo e seu dormir é desespero ${ }^{3}$.

Conquanto tanto o homem quanto o animal se relacionem com a natureza inorgânica, o primeiro é um ser genérico, e o segundo, um ser específico. Uma vida de gênero (Gattungsleben) se define pela capacidade de possuir uma consciência universalizante da natureza inorgânica, fazendo com que a consciência do sujeito possa estabelecer domínio sobre a dinâmica do externo sensível - o homem adquire consciência por sua relação com os meios de vida da natureza e passa a estabelecer a capacidade de engendrar a apreensão de uma ciência das leis físicas e do belo da natureza como universais.

Ao mesmo tempo, porém, que essa vida espiritual faz parte do ser de gênero, a universalidade do homem não deve ser entendida apenas como um domínio da consciência, mas também com a vida corpórea, pois o gênero, sendo genérico, só pode se expressar como alguma espécie não restrita, mas de modo múltiplo e livre. Assim, a natureza é uma extensão corpórea do homem, que a toma como sua espécie e por isso é capaz de alcançar finalidades verdadeiras em sua atividade. A condição do homem é ser mental e corporalmente interconectado com a natureza, e assim ser também não proprietário dela, mas aquele que a exprime na sua própria expressão, uma vez que as finalidades da atividade humana se dão no interior das condições materiais inorgânicas (MARX, 2004, p. 84), e assim são também expressões da própria natureza através do homem. O objeto encontrado em sua forma mesma, e não enquanto objeto para o outro, permite que se o apreenda não enquanto coisa a se apropriar - proclamar e predicar - mas enquanto sua essência. Esse é o processo emancipatório que livra o homem da alienação. O que no sujeito não se reduz a ser para o outro é aquilo que nele não se põe sob espécie alguma.

3 Se poderíamos considerar que Marx analisa de uma perspectiva otimista - levando em conta o modo como a Teoria Crítica diagnosticou o advento da mídia no século XX - a capacidade, isto é, a incapacidade de os modos de produção alcançarem a vida privada, vemos que é só porque ela sequer existe para os despossuídos do século XIX. 
A vida genérica é a consciência da atividade vital como um distanciamento da vida física, um ter a vida como objeto que permite a ação livre não imediata dos animais. E é isso que fundamenta a capacidade de produção do belo, pois o homem como gênero é capaz de se ater livre e universalmente à natureza inorgânica, e fazer da expressão possível dela uma expressão também sua, como espécie do gênero: extrair o belo da natureza para expressar uma condição de sua consciência é uma relação entre-expressiva homem-natureza.

\section{Diálogos}

\section{II.I. Subjetivo universal}

A partir das definições propostas, pode-se falar, tanto em Marx quanto em Kant, da noção de um universal subjetivo do belo, embora por distintos modos. O universal subjetivo de Kant se dá por um princípio de adesão (KANT, 20I6, p. IIO) à noção de que um objeto belo não pode possuir finalidade conceitual ou moral, assim como não pode ser baseado apenas no sentidos, mas que de qualquer modo é sempre realizado por uma experiência autônoma do próprio juízo no qual a forma é mera aparência, uma projeção incitadora do que realmente é a experiência do belo puro: o ânimo livre-jogante. Interpretamos então que a percepção reflexiva da autonomia da faculdade é uma experiência universal que ao mesmo tempo permanece no campo subjetivo da relação não determinante do juízo com a mera forma.

As finalidades conceitual e moral retiram o objeto da imaginação e do campo meramente formal e de incitação para juízo, de modo a torná-lo um conceito do entendimento, de um lado, e um direcionamento da vontade para o bem, de outro. Assim considerada, essa questão põe Kant em posição crítica à arte clássica - àquela parte do cânone ocidental fundado na ideia de que a perfeição e o bem seriam analogias de belo, quando é necessário distinguir que o perfeito é da ordem da multiplicidade do conceito que se integra, e portanto é lógico, e que o bom é da ordem da vontade racionalmente determinada, e portanto é prático. Ambos são interesses (KANT, 20I6, p. IO3). Para Kant, a estética surge por uma necessidade de apreender uma dimensão da natureza que não se submete ao método simplesmente lógico, a partir do qual se considera a legislação mecânica da natureza. A dimensão do belo surge, por sua vez, como aquilo que é capaz de incitar as faculdades da imaginação a um jogo harmônico através do qual elas possam se dispor a uma apresentação desse 
objeto como aquilo que as põe em conformidade a fins, mas sem a necessidade de se determinar. É esse excitamento que deve ser aderido como o princípio universal que determina a beleza de um objeto representado (KANT, 20I6, p. IO7-IO8).

Em Marx, o universal parte do gênero enquanto detentor de um corpo estendido por toda a natureza e pela reflexão que analisa e seleciona desejos, que faz com que sua consciência seja produzida entre-expressivamente. Isto é, a natureza é fornecedora dos meios de vida do homem, e por isso é de certo modo a condição de sua expressão, e o homem, sendo genérico, apropria-se dessas condições para exprimir sua própria consciência dentro das possibilidades - e se considerarmos assim, o homem é capaz de conhecer a finalidade inerente do objeto inorgânico ao produzi-lo livremente. O que fundamenta o universal subjetivo em Marx é, portanto, a concepção de que o objeto produzido livremente tem uma finalidade revelada à consciência dentro dessa relação entre-expressiva, e assim a arte é uma expressão subjetiva que é universal por ter uma finalidade determinada ou revelada pela consciência.

Com efeito, embora o jovem Marx não pareça estar preocupado com o problema da recepção estética tal como Kant está, a condição para o aparecimento do belo em ambos leva em conta uma dimensão da natureza que é condição para as formas belas naturais, bem como para uma finalidade que deve ser universalizada sem abrir mão de seu caráter subjetivo, conquanto se deva enfatizar que a finalidade em Kant é a conformidade a fins, a disposição à finalidade, e não uma em si.

Uma passagem da terceira crítica, em um parágrafo especialmente voltado à noção de ideal de belo, faz-se peça-chave para a compreensão da proximidade de pensamento sobre esse objeto entre os autores, que também fundamenta a perspectiva de que, ao menos na juventude, Marx desenvolveu parcamente o que poderia ser considerado um pensamento autêntico no campo da estética, sendo ainda, ao menos neste campo, legatário de um idealismo que certamente perpassa tendências kantianas:

Um ideal de flores belas, de um mobiliário belo, de um belo panorama não pode ser pensado. Mas tampouco se pode representar o ideal de uma beleza aderente a fins determinados, por exemplo, de uma bela residência, de uma bela árvore, de um belo jardim etc.; presumivelmente porque os fins não são suficientemente determinados e fixados pelo seu conceito, consequentemente a conformidade a fins é quase tão livre como na beleza vaga. Somente aquilo que tem o fim de sua existência em si próprio - o homem, que pode determinar ele próprio seus fins pela razão -, ou onde necessita torná-los da percepção externa, todavia, pode 
compará-los aos fins essenciais e universais e pode então ajuizar também esteticamente a concordância com esses fins; este homem é, pois, capaz de um ideal da beleza, assim como a humanidade em sua pessoa, enquanto inteligência, é, entre todos os objetos do mundo, a única capaz do ideal da perfeição (KANT, 20I6, p. I29, grifos do autor).

\section{II.II. Produção e recepção interessadas e desinteressadas}

A produção do belo em Kant e em Marx tem como condição primeira o livre agir. No primeiro, a liberdade se dá na reflexão da faculdade do juízo, na percepção da autonomia e no livre exercício das faculdades que produz um sentimento de agradável e que não tem em si seriedade nem finalidade alguma, mas antes leveza e relaxamento através da apresentação que as excita sem se determinar. No segundo, a liberdade é a consciência da ação produtiva, de modo que poderíamos considerar que é a perspectiva do sujeito sobre sua atividade vital que produz nele a satisfação e o tira da forma de produção alienada, enquanto coisa física numa relação mecânica com outras coisas físicas. Existe uma prerrogativa da percepção de autonomia do sujeito em ambos os filósofos, neste aspecto. E para além disso, esses exercícios da liberdade são desinteressados - em suas próprias definições do que é interesse.

Para Kant, o interesse é determinado ou pelas finalidades do conceito (lógica e prática) ou pelas do aprazimento subjetivo particular (necessidade e desejo a serem saciados), e portanto o belo, embora gere o sentimento de prazer (Lust), não o faz de modo particular, mas universal, e no aspecto lógico é apenas aparente, estando somente em prontidão de determinar. Para Marx, a liberdade do ser genérico na produção se dá pela noção de que o homem é um ser com consciência, e que portanto não cria apenas por necessidades físicas imediatas, como os animais, mas de modo universal. O homem possui vontades que podem desertar da ideia, de maneira a cancelar o que está em potência de acontecer. Sua necessidade vital pode ser preterida em relação a outros fins que não dizem respeito à sua adequação potencial. $O$ homem conhece a contingência e a possibilidade; o animal, a necessidade e o necessário. O homem sempre lida com uma relação de possíveis que excede a sua realização efetiva é no excesso de possibilidades que surge como reprodutor de toda a natureza, e não apenas de si, de suas adequações e necessidades. $O$ interesse aqui é essa demanda física para a qual o belo seria irrelevante diante da eficiência de um abrigo ou da alimentação ou mesmo da procriação, e que o homem supera por não ser uma espécie, mas ter uma vida de gênero que o torna capaz de se 
relacionar com a natureza de modo universal-espiritual ao invés de somente imediato-corpóreo.

Todavia, enquanto em Kant o belo puro é apenas um jogo das faculdades excitadas por uma mera forma, em Marx parece haver também a necessidade de uma expressão, de uma aplicação da atividade vital na produção de uma finalidade possível à matéria inorgânica coadunada à consciência. Nesse sentido, poderíamos estabelecer uma primeira interpretação, na qual a condição expressiva da beleza em Marx cria possibilidades inúmeras de expressão que podem perpassar finalidades diversas, e que necessariamente estão tensionadas pelas questões históricas, sociais e morais que produzem a dinâmica dos possíveis da apropriação. Essa perspectiva parece ser relativamente problemática de examinar, pois implica a noção de que essa consciência "romântica" de Marx pode ser limitada pela noção de que está em uma relação interdependente com a natureza inorgânica, mesmo que a consideremos, tal como fazemos aqui, de um ponto de vista mais abstrato - ora, isso a torna historicamente determinada em suas possibilidades de expressão da consciência e de expressão da matéria inorgânica. A recepção de uma produção artística bela em Marx, diferentemente do lúdico kantiano, não pode se esquivar de uma finalidade historicamente crítica de seus próprios limites, considerando um campo prático de produção da arte em que o ser do gênero é de certo modo parcial e está imbricado nos modos de produção em todos os tempos da história humana até aqui. Ao mesmo tempo, uma crítica inversamente proporcional poderia ser feita a Kant, na medida em que interpreta que sua obra se atém tão somente ao belo, e a arte ganha papel oblíquo na terceira crítica, o que faz de sua filosofia estética algo de propedeuticamente submetido, para que pudesse haver uma aplicação prática, a desenvolvimentos posteriores - os quais têm seu primeiro momento frequentemente identificado em Friedrich Schiller.

Portanto, deve-se considerar que ambos mantêm o princípio de desinteresse como essencial para a produção do belo, mas quando se trata da recepção, apenas Kant o preserva - tanto pelo que foi dito no parágrafo anterior, acerca do alcance de sua teoria, quanto mais propriamente pelo fato de que produção e recepção se confundem, ou sequer se distinguem, na representação estética do belo puro (KANT, 20I6, p. I25). Em Marx, no entanto, a recepção parece ser dupla, pois, considerando o passo à frente que demos para chegar em nossa análise da arte, é inerente a um interesse expressivo dos moldes kantianos, embora o desinteresse do livre esteja lá, na relação dos fatores históricos e inorgânicos. Considerando a noção de beleza segundo leis, porém, poderíamos deduzir que para Marx existem objetos belos na natureza, os quais o homem universaliza e que não necessariamente dependem da expressão do 
sujeito. O que parece comprovar isso é o modo como Kant vê a forma bela natural. Ao considerar apenas o objeto belo, que poderia não ter necessidade expressiva subjetiva, mas apenas ser produzido segundo as leis da beleza postas na natureza, deduziríamos que o belo não teria uma finalidade lógica, mas universalmente aprazível por ter sua finalidade determinada ou revelada na relação consciência-natureza, levando em conta que uma se expressa através da outra (MARX, 2004, p. 85).

Mas há outra interpretação possível da capacidade de engendramento da arte em Marx, mais favorável ao teor romântico de seu pensamento de juventude. Pois embora Marx se afaste do Romantismo como pensamento político-social nostálgico, que almeja, ao menos de uma certa perspectiva mais superficial, um retorno - pois para o filósofo se trata de superar pela despossessão toda a estrutura do domínio privado dos meios de produção -, podemos concluir que a relação dos sujeitos com os objetos belos se caracteriza por uma internalização, em que o sujeito consigo mesmo se vê pelo objeto. E em âmbito social, abarca-se uma reflexibilidade do homem que vai além das condições histórico-sociais, ou materiais, expressando-se também como forma de ampliação do sujeito pelo reconhecimento do objeto como possibilidade do humano que ultrapassa a sua relação consigo mesmo.

Interessa considerar que a noção de gênero como uma relação metabólica com a natureza, na qual o indivíduo lida com sua própria expressão livre diante das possibilidades específicas do meio e da matéria inorgânica, e portanto precisa a todo momento se relacionar com o externo e ele mesmo ser também aquilo que exprime a natureza, como parte dela, pode fornecer as bases para uma aproximação da noção de gênio. Não à toa, gênero, gênio, gênese, gene e geração partilham um evidente parentesco etimológico concernente às noções do produzir, engendrar.

Em uma abordagem mais geral, o gênio como expressivo da arte surge como contraposição ao ideal técnico-comunicativo do Classicismo, marcando-se pela singularidade disruptiva, e não pela adequação - tanto às leis e formas quanto a si mesmo enquanto indivíduo. Agamben (2007, p. I6), ao tratar dessa noção, formula que aquilo que fundamenta a condição do gênio não é apenas um elemento singular de sua individualidade, mas antes uma impessoalidade, com a qual ele tem que lidar como aquilo que o excede e o disfuncionaliza enquanto indivíduo presente.

Compreender a concepção de homem implícita em Genius equivale a compreender que o homem não é apenas Eu e consciência individual, mas que, desde o nascimento até à morte, ele convive com um elemento impessoal e pré- 
-individual. O homem é, pois, um único ser com duas fases, que deriva da complicada dialética entre uma parte (ainda) não identificada e vivida, e uma parte já marcada pela sorte e pela experiência individual (AGAMBEN, 2007, p. I6).

O gênio é também aquilo que vem antes do indivíduo, que o gera, e neste sentido o gênio é, como expressão, análogo do gênero em Marx, como aquilo que se expressa apenas segundo as condições entre-expressivas da natureza, ou seja, que também se expressa no indivíduo e que o gera. Com efeito, o gênero e o gênio não devem ser considerados como elementos historicamente integrados - no sentido de uma limitação das possibilidades de expressão na natureza por uma determinação constituída pela dominação material de uma casta - mas antes como aqueles aspectos capazes de disfuncionalizar os meios adequativos postulados e romper, pela expressão, com as possibilidades vigentes em prol de uma relação indeterminada, pois não se trata de expressar o indivíduo, e sim do que se produz de sua fricção com aquilo que lhe é impessoal, que o nega e que lhe tira da posição de núcleo para passar à própria forma e ao espectador, como uma passagem ao objeto que, de uma maneira ou de outra, é a própria natureza, que é meio para todos os seres de gênero conhecerem, perceberam e se expressarem e por isso se realiza como dimensão supraindividual que dirige o gênio e o ser do gênero à finalidade do objeto.

É aqui que se rompe o que no sujeito poderia ser apenas a expressão de uma concepção artística submissa ao ethos dos que dominam os meios de produção, podendo ser mesmo fonte de horror para esses ${ }^{4}$. Passa-se da órbita autor-obra da estaticidade do ideal para a relação de abertura ao fascínio e desestabilização, em que o gênio produtor se faz distante e o receptor passa a ser o centro de gravidade (LYOTARD, I997, p. IOI). O sublime kantiano, muito mais que o belo, se põe nesse lugar dialético daquilo que não se deixa integrar e permanece numa constante relação de curto-circuito entre indivíduo e natureza. Para Kant, o conceito de sublime se dá como aquilo que estabelece, por um lado, uma relação de potência da natureza contra nossas potências físicas de subsistência e potências racionais de resistência (sublime dinâmico) e, por outro, como a desmedida absoluta da natureza enquanto ideia negadora da atividade representativa, uma vez que produz disfunciona-

4 Relação que é problemática estética central e amplamente abordada nos séculos XVIII e XIX, de modo a ser arbitrariedade muito maior afirmar que o jovem Marx não dialoga com ela do que afirmar que, sim, enquanto aluno de Hegel e figura do século XIX, todo esse contexto tem uma base de correlação bastante sólida com seu pensamento, tal como agora analisamos. 
lidades na faculdade figurativa do homem, que é a imaginação (sublime matemático). Mas o que aparece como verdadeiramente interessante na abordagem kantiana é que também na Crítica da faculdade de julgar observamos se realizar um giro copernicano,

[...] pois o autêntico sublime não pode estar contido em uma forma sensível, já que só diz respeito a ideias da razão - as quais, mesmo não sendo possível uma exposição que lhes fosse adequada, são, justamente por essa inadequação (que pode ser expressa sensivelmente), evocadas e reavivadas na mente (KANT, 20I6, p. I42).

Ora, embora para Kant o conflito que produz o sublime se dê quase integralmente nas faculdades do sujeito, poderíamos considerar o problema da determinação histórica do indivíduo como aquilo que produziria esse conflito na perspectiva da teoria marxista, como a limitação pela qual a natureza o impulsionaria a outras condições expressivas indeterminadas e indefinidas diante dessa alienação, que exige uma quebra de sua individualidade - o que, de certo modo, é a própria condição de sua consciência enquanto ser desprovido de espécie; ser que universaliza e que se entre-exprime com a natureza. A vida de gênero exige uma relação metabólica supraindividual com o meio.

Diante disso, não é estranho que determinemos no próprio teor "romântico" do jovem Marx algo que tem sua raiz já no kantismo, e mesmo que se considere que a vida de gênero como entre-expressão da consciência do sujeito e da natureza marque uma proximidade grande com o que Kant vai considerar um artista de gênio: aquele que não exatamente é capaz de imitar a natureza, pois não se trata de uma beleza determinada, mas de imitar as finalidades da natureza, como aquilo que é próprio da faculdade do juízo. Isto é, é a dinâmica da finalidade que ativa o ânimo sem determiná-lo, pois toda observação universalista do juízo é mera projeção do sujeito sobre a natureza em busca de avançar o entendimento, sem necessariamente efetivar essa universalidade, pois é próprio do entendimento que a determinação se dê do universal ao particular, e não o contrário.

Daí porque existe uma certa conciliação entre entendimento e razão, na medida em que o juízo promove esse espelhamento de legalidades entre um e outra: o entendimento passa a agir como se houvesse finalidade na natureza, e a razão percebe nessa legalidade do entendimento a possibilidade de uma realização na natureza de uma vontade final, agindo como se pudesse determinar um fim moral último. Isso faz com que o gênio, para ser capaz de produzir obras que se mostrem propícias ao estado mental de belo como atividade finalística sem fim, precise ser dotado de um talento dado a ele 
pela natureza - ele precisa intuir as regras de finalidade da natureza e aplicá-las à obra. Tanto mais bela ela será quanto mais capaz de intensificar o livre jogo do juízo de gosto. Enfim, com isso vemos que a entre-expressão da vida de gênero em sua produção livre das possibilidades do meio - que se tornam próprias a ele na medida em que o próprio indivíduo lhe é organicamente situado - aproxima-se não apenas da noção de gênio que se realiza sublimemente, mas também da que se realiza de modo belo. Não muda, porém, a perspectiva de que o gênio belo pode acabar por se enquadrar nas limitações e condicionantes históricos-materiais que o gênio sublime parece quebrar, embora não saibamos em que medida o gênio pode se historicizar numa visão tão formal quanto é a kantiana.

Por outro lado, outros muitos problemas surgem ao pensarmos na radicalização da autonomia do sujeito e da forma, propiciada pela tecnologia, em relação à natureza. Com os meios de produção em massa, também a arte não se alienaria do sujeito como um objeto que não lhe é próprio - ou mesmo que lhe é demasiado próprio para ter um teor universal? Quer-se dizer, as obras de arte que partem de uma certa produção entre-expressiva dependem da atualização das potências do meio a partir de uma percepção de finalidade do sujeito que é também uma percepção de finalidade da natureza, na medida em que se trata de um ser de gênero que se especifica ao produzir. Essa consciência, no entanto, parece só poder se dar na medida em que o indivíduo está organicamente situado na natureza e tem com ela uma relação sensorial ou, no caso kantiano, de um estado mental que harmoniza a obra e o sujeito.

Em que proporção os meios de produção, na medida em que são meios, ou seja, que passam a intermediar essa relação, não tornam menos potentes os estímulos artísticos? A tecnologia atualiza a potência alienadora do específico, na medida em que o fim da produção da obra passa a ser um largo consumo de um objeto, tirando a expressão artística do que seria seu campo de atuação mais efetivo. Esse campo se dá numa necessária interação entre a consciência do sujeito e da cultura na produção da obra, e isso fica claro quando pensamos, seguindo um exemplo de Marx, que a condição de possibilidade para a poesia épica de Homero era sua transmissão oral, pois era através dessa prática que os sujeitos se faziam transmissores de sua própria cultura, e portanto os meios de sua própria arte e religião.

Mesmo a noção de autor, isto é, a noção da poesia e da arte em geral como uma propriedade individual que deve ser assimetricamente produzida por um sujeito e consumida por outros, só pode surgir com a imprensa, isto é, com a perda dessa relação sem mediações, em que o poeta encarna a Musa e tem sua autoridade como uma atribuição não exatamente sua, mas de um âm- 
bito supraindividual ${ }^{5}$. A autoria, portanto, na medida em que é determinada materialmente, aliena a arte como expressão cultural orgânica de um povo, desprovida de uma apropriação individual propriamente dita. Isso respalda problematicamente também a concepção kantiana de uma arte bela, na medida em que surgem expressões artísticas abstratas, e o artista de gênio passa a ser não um sujeito provido de um certo talento que deve ser submetido a um trabalho em prol da aparência de finalidades, mas alguém capaz de inovar conceitualmente, radicalizando a autonomia formal da arte para fora mesmo dessa peculiar mimese das finalidades, e não das imagens naturais.

Passando aos seus próprios conceitos e à expressão de uma internalidade formal e psicológica que não encontra meios de adesão, os ruídos passam a ser grandes demais para que a arte se fie em um paradigma teleológico, pois a natureza tal como Kant a concebe não leva em conta o abstrato das expressões psicológicas ou das ideias formais. Na medida em que a arte bela é constituída como um estímulo de belo que reflete uma certa organização natural fundada numa perspectiva teleológica, e assim ativa no sujeito as faculdades que tentariam dar conta dessa organização e que se percebem, no processo, autônomas e livre-jogantes, a quebra do paradigma teleológico significa a quebra do próprio paradigma de belo. E isso se mostrou manifestamente verdadeiro através das vanguardas artísticas do século $\mathrm{XX}$.

\section{Considerações gerais}

Ao contrário do que inicialmente deduzimos, mesmo Marx em juventude não se limita a uma apropriação que se diria literal das noções estéticas idealistas. Pois embora tenhamos identificado muitas proximidades e literalidades entre o pensamento do autor e o de Kant nesse campo, a todo momento a noção material se pronuncia, englobando a teoria sócio-histórica como orbitante da noção de ser de gênero, e portanto condicionando-o a uma perspectiva não tão formal do sujeito quanto é aquela posta em Kant.

O universal subjetivo está presente em ambos, mas em Marx ele se dá por uma certa noção de reflexibilidade universal de características providas pelo

5 Horácio é bem claro a respeito disso, quando diz, em sua Carta aos Pisões: "Tampouco se deve começar como certo autor cíclico outro: 'Cantarei a sorte de Príamo e a guerra ilustre...' Que matéria nos dará este prometedor, digna de tamanha boca aberta? Vai parir a montanha, nascerá um ridículo camundongo. Bem mais acertado andou este outro, que nada planeja de modo inepto: 'Fala-me, Musa, do herói que, após a tomada de Tróia, viu os costumes e cidades de muitos homens'!" (HORÁCIO, 20I6, p. 59). 
meio, o que possibilita à expressão artística um caráter acessível não determinado enquanto sublime, assim como também possibilita a ideia de belo similar ao belo natural kantiano, que é simplesmente universalizado como uma parte da natureza que não se submete à lógica, mas se expressa esteticamente. Assim, a liberdade na produção e recepção se mantém em ambos os autores, pois se trata de afirmar na produção, em Marx, uma potencialidade do sujeito enquanto ser de gênero, ou seja, sua liberdade coadunada à sua capacidade de universalização da natureza. Em Kant, em se tratando da estética, a liberdade se dá não no âmbito prático, mas na relação livre. Todavia, como dito, é também possível uma leitura de proximidade entre o sublime kantiano e uma noção de expressão artística do gênero entendido como gênio, pois se trata de compreender que a expressão do ser do gênero nunca está totalmente determinada por suas condições histórico-sociais, mas visa sempre a afirmação de sua liberdade enquanto aquilo que não se determina, que não é um indivíduo hermético, mas antes um ser supraindividual.

Este foi um trabalho de delineamentos mais do que de aproximações, mas sobretudo de delineamentos sutis, que amiúde deram margem não só a uma, mas várias interpretações ainda neste escrito. Gruzando medidas, buscou-se um mapeamento possível dessa relação pelas próprias potencialidades de desenvolvimento dos textos-fonte, e embora isso tenha nos tirado uma leitura englobadora e autêntica, pôde responder às questões iniciais pelo diálogo franco e claro entre os autores.

\section{Referências}

AGAmBEN, G. Profanações. São Paulo: Boitempo, 2007.

HORÁCIO. Arte poética: Epistula ad Pisones. In: ARISTÓTELES; HORÁCIO; LONGINO. A poética clássica. São Paulo: Cultrix, 20i6. p. 59.

KANT, I. Crítica da faculdade de julgar. São Paulo: Vozes, 2016.

LYOTARD, J.-F. O inumano. Lisboa: Estampa, I997.

MARX, K. Manuscritos econômico-filosóficos. São Paulo: Boitempo, 2004.

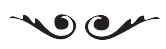

Rodney Ferreira é graduado em Filosofia pela Universidade de São Paulo. rodneydesu@gmail.com 